\title{
MiR-124-3p/ZC3H15 Regulates Gastric Cancer Progression by Blocking FBXW7 Mediated Degradation of c-Myc
}

Jianbing Hou

Southwest University

Yudong Liu

Southwest University

Du Yan

Chongqing University

Pan Huang

Southwest University

Zhongze Wang

Southwest University

Hongyu Gu

Southwest University

Chao Lan

Southwest University

Shengjun Geng

Southwest University

Hongjuan Cui ( $\nabla$ hcui@swu.edu.cn )

Medical Research Institute, Southwest University

\section{Research}

Keywords: ZC3H15, Gastric cancer (GC), c-Myc, FBXW7, miR-124-3p

Posted Date: August 1st, 2020

DOl: https://doi.org/10.21203/rs.3.rs-48782/v1

License: (c) (i) This work is licensed under a Creative Commons Attribution 4.0 International License.

Read Full License 


\section{Abstract}

BACKGROUND: Zinc finger CCCH-type containing 15 (ZC3H15), a highly conserved eukaryotic protein, was involved in tumorigenesis and may be a potential biomarker in hepatocellular carcinoma (HCC) and acute myeloid leukemia (AML). However, the biological role of ZC3H15 in gastric cancer (GC) is unclear.

METHODS: The potential correlation between $\mathrm{ZC} 3 \mathrm{H} 15$ expression and GC prognosis was assessed based on the patient data analysis. The biological role of $\mathrm{ZC} 3 \mathrm{H} 15$ in regulating cell proliferation and metastasis was evaluated in vitro and in vivo. In addition, the potential mechanism of $\mathrm{ZC} 3 \mathrm{H} 15$ was investigated.

RESULTS: we found that ZC3H15 expression was positively correlated with GC progression, including cell growth, metastasis and cancerogenesis. Through further investigations, we found that ZC3H15 could modulate c-Myc protein stability via suppressing the transcription of FBXW7, which was mainly responsible for c-Myc degradation. In addition, we revealed that miR-124-3p, a tumor suppressor of GC, was negatively associated with $\mathrm{ZC} 3 \mathrm{H} 15$. We revealed that miR-124-3p was a critical upstream modulator of ZC3H15 in GC.

CONCLUSIONS: Taken together, our studies unearth the important roles of ZC3H15 in GC development and suggest that miR-124-3p/ZC3H15/c-Myc axis may be a potential target for the treatment of GC.

\section{Background}

Gastric cancer (GC) is a seriously threatens for human life and health [1-3]. Various risk factors have been reported to play a critical role for the development of GC, such as familial inheritance, helicobacter pylori infection, and unhealthy dietary habits [4-6]. At present, primary treatment of GC include surgery, radiation, chemotherapy therapy, and targeted therapy. Early detection of GC is important for the overall prognosis of patients with GC [7]. However, early detection and diagnosis is not carried out effectively due to the poor understanding the pathogenesis and molecular mechanism of GC [8]. Therefore, an in-depth investigation into the underlying mechanism and efficient molecular targets is still of great significance for the treatment of GC.

Ubiquitous expression of $\mathrm{ZC} 3 \mathrm{H} 15$ was revealed by the Human Multiple Tissue Northern Blot in various normal human tissues [9]. $\mathrm{ZC} 3 \mathrm{H} 15$, its gene locus was at human chromosome $2 \mathrm{q} 32.1$, was identified as an immediate early erythropoietin response protein due to it was likely ortholog to mouse immediate early response erythropoietin 4 [9-11]. ZC3H15 is a classical $\mathrm{CCCH}$-type zinc finger protein, suggesting it may be function as a transcription factor in cell signaling. In addition, $\mathrm{ZC} 3 \mathrm{H} 15$ proteins also contain a conserved DRG family regulatory protein (DFRP) domain, which is essential for the association of ZC3H15 with DRG [12]. Moreover, Gianni et al. has revealed the interaction of ZC3H15 with TRAF2, which was responsible for the activation of NF-KB signaling [13-17]. Indeed, ZC3H15 act as an important role involved in cell proliferation, apoptosis, cell adhesion, and transcription, and dysregulation of $\mathrm{ZC} 3 \mathrm{H} 15$ has been reported in hepatocellular carcinoma (HCC) and acute myeloid leukemia (AML) [18]. However, the biological role of ZC3H15 expression in GC is unclear. 
The c-Myc oncoprotein, a transcription factor frequently upregulated in varieties of human neoplasms, is related to many physiological progressions such as cell survival, chemoresistance, and tumorigenesis [19]. Owing to the critical role of c-Myc in modulating cellular pathways, its expression is tightly regulated. The regulatory mechanisms of c-Myc are majorly included transcriptional regulation, acetylation, phosphorylation and proteasomal degradation [20; 21]. F-box and WD repeat domain containing 7 (FBXW7), a known E3 ubiquitin ligases involved in ubiquitylation and proteasomal degradation of c-Myc, is an important tumor suppressor and is commonly dysregulated in human cancers [22; 23]. Expression of FBXW7 is negatively correlated with the tumor malignancy of human cancers [24; 25]. Therefore, a better understanding of the mechanisms of the regulation of FBXW7 expression may be effective in therapy against cancer.

The overexpression of ZC3H15 was found in GC patients according to our study. In order to identify the underlying mechanism of overexpression in $\mathrm{ZC} 3 \mathrm{H} 15$ expression, we put the focus on microRNAs (miRNAs). miRNAs, a kind of small endogenous noncoding RNAs, are crucial mediators for posttranscriptional regulation, and can act as oncogenes or onco-suppressors [26-28]. One of the primary ways that miRNAs regulate cancer progression is through mRNA degradation. miRNAs could bind the specific sequences of the target mRNA and then modulate the gene expression [29; 30]. miR-124-3p has been proven to be a crucial regulator in cancer progression, including breast cancer, cervical cancer, bladder cancer, and gastric cancer [31-34]. ZC3H15 is a predicted target gene of miR-124-3p according to the starBase. However, the mechanism by which miR-124-3p regulates $\mathrm{ZC} 3 \mathrm{H} 15$ in human cells is unknown.

In this study, we demonstrated that ZC3H15 modulated cell proliferation, migration, invasion, and tumorigenesis via a c-Myc-dependent signaling pathway. $\mathrm{ZC} 3 \mathrm{H} 15$ increased the protein stability of c-Myc by inhibition of FBXW7 transcription. In addition, we further demonstrated that miR-124-3p was a key upstream regulator of $\mathrm{ZC} 3 \mathrm{H} 15$ in GC. Taken together, these data indicated that miR-124-3p/ZC3H15/cMyc axis may be a potential therapy target for GC.

\section{Materials And Methods}

\section{Cell culture and transfection}

The GES-1 cells, GC cell lines, and embryonic renal cell line 293FT were purchased from the American Type Culture Collection (ATCC, Manassas, VA, USA). The HGC -27 cells was cultured in MEM (Minimum Essential Medium) supplement with penicillin and streptomycin(P/S) and fetal bovine serum (FBS); The other GC cell lines and GES-1 cells were cultured in RPMI-1640 (Roswell Park Memorial Institute-1640) mediums supplement with P/S and FBS. 293FT cell line was cultured as previously described [35]. The MEM, RPMI-1640 and DMEM meida, FBS, and antibiotics were obtained from Thermo Fisher Scientific, Inc. (Waltham, MA, USA). 
Sequences of the shZC3H15 and shFBXW7 were obtained from GenePharma Co., Ltd (Shanghai, China), and were listed as below:

shZC3H15\#1: CAGATCCCAAGTCTGTAGTAT

shZC3H15\#2: CCTAGAATCAACAGGATGTTT

shFBXW7\#1: CCAGTCGTTAACAAGTGGAAT

shFBXW7\#2: CCAGAGAAATTGCTTGCTTTA

Vector encoding of human ZC3H15 were constructed by PCR-based amplification, and the primers used were listed as below:

ZC3H15-F-(ECORI): CCGGAATTCATGCCCCCCAAGAAAC

ZC3H15-R-(Notl): ATTTGCGGCCGCTCATTCTTCTAAATCAAGTGTATTT

Lentivirus was produced as previously described [35].

\section{Reagents}

Dimethyl sulfoxide (DMSO) was obtained from Sigma Aldrich (MO, USA). The ZC3H15 (cat. no. 26241), CyclinD1 (cat. no. 60186), c-Myc (cat. no. 10828) and Tubulin (cat. no. 11224) antibody were purchased from Proteinch (Wuhan, China); The FBXW7 (cat. no. ab74054) and Ki-67 (cat. no. ab92742) was purchased from Abcam (Shanghai, China); Flag (cat. no. 14793), CDK4 (cat. no. 12790), CDK6 (cat. no. 13331), MMP7 (cat. no. 3801) and N-cadherin (cat. no. 13116) antibody were purchased from Cell Signaling Technology (Beverly, MA, USA).

\section{Immunohistochemistry staining}

Tumor specimen was embedded in paraffin and sectioned into $5 \mu \mathrm{m}$ thick sections, and then deparaffinized and hydrated. The sections were performed by microwave heating for antigen retrieval, and then incubated with endogenous peroxidase and blocking with goat serum. After quenching for primary antibodies at $4^{\circ} \mathrm{C}$ and secondary antibodies at room temperature, sections were covered with $D A B$ (diaminobenzidine) for visualizing the staining.

\section{Cell viability and proliferation assays}

MTT assay was performed to examine the cell viability of indicated GC cell lines. Cells ( $1 \times 10^{3}$ cells/ well) were cultured in the 96-well plates, and then were detected according to the manufacture's protocol. 


\section{BrdU staining}

For BrdU staining, indicated cells were seeded into 24-well plates. After incubated with BrdU (Sigma) and fixed in $4 \%$ PFA, cells were treated with $1 \mathrm{~mol} / \mathrm{I} \mathrm{HCl}$ and $5 \%$ goat serum. Then, cells were incubated sequentially with primary antibody against BrdU, and Alexa FluorR 594 secondary antibody. DAPI (4',6diamidino-2-phenylindole) was used for nuclear staining.

\section{Western blot analysis and Co-IP}

For Co-IP assay, cells were lysed in IP lysis buffer (Sigma) and then incubated on a rocker with antibody as well as IgG at $4{ }^{\circ} \mathrm{C}$ overnight. After incubation with Protein A/G PLUS-Agarose, cell lysate were washed by PBS and resolved by sodium dodecyl sulfate-polyacrylamide gel electrophoresis analysis. Western blotting was performed as previously described [36].

\section{Ubiquitination assay}

For the ubiquitination assay, indicated plasmids were transfected into the $293 \mathrm{FT}$ cells. MG132 $(50 \mu \mathrm{g} / \mathrm{ml}$, Selleck, Houston, TX, USA) was added into the cells for $6 \mathrm{~h}$ before harvesting. Cells were lysed and then performed following the same protocol used in Co-IP.

\section{Turnover assay}

The cells were transfected with indicated plasmids, and then a final concentration $(100 \mu \mathrm{g} / \mathrm{ml})$ of $\mathrm{CHX}$ was added into the media. After harvesting at the indicated time points, cell were lysed and analyzed by Western blotting.

\section{Quantitative and RT-PCR}

Total RNA was harvested from the indicated cells and then reversely transcribed into cDNA by iScript cDNA Synthesis Kit (BioRad, \#170-8891). The expression of mRNA was measured by using a Roche LightCycler Real-Time PCR System. Primers for RT-PCR assays were listed as Table II.

\section{Luciferase reporter assay}

Cells were transfected with shZC $3 \mathrm{H} 15, \mathrm{ZC} 3 \mathrm{H} 15$ or miR-124-3p mimics together with the indicated reporter (FBXW7, ZC3H15-WT, or ZC3H15-Mut) or control plasmid. Dual luciferase assay was performed by using the Dual-Luciferase ${ }^{\circledR}$ Reporter Assay System (Promega, \#E1910). The promoter fragments of FBXW7, ZC3H15-WT, and ZC3H15-Mut were purchased from Wuhan GeneCreate Biological Engineering Co., Ltd. 


\section{Chromatin immunoprecipitation}

Chromatin was isolated from $2 \times 10^{7} 293 \mathrm{FT} /$ Vector and 293FT/Flag-ZC3H15. ChIP assays were performed using the EZ-ChIPTM kit (Millipore, CA, USA), and then detected according to the manufacture's protocol. The primers used in ChIP assays are listed as Table II.

\section{Soft agar assay}

For the soft agar assay, $0.4 \times 10^{3}$ cells were mixed with $0.6 \%$ agarose (Sigma-Aldrich, USA) in RPMI- 1640 medium and then plated into 12 -well plates containing a solidified bottom layer $(0.3 \%$ agarose in medium).

\section{Animal experimental procedures, tumour xenograft experiment, and lung metastasis assay}

All animal studies were approved by the Institutional Animal Care and Use Committee of Southwest University. Four-week-old female nude mice were purchased from Beijing Animal Research Center and were housed in the SPF room. For the tumor xenograft experiment, mice were randomly divided into three groups. HGC-27 cells $\left(1 \times 10^{6}\right)$ stably transfected with shGFP, shZC3H15-1 and shZC3H15-2 were subcutaneously injected into the mice in 18 November, 2019. Isoflurane anaesthesia system, which could help animals enter an anaesthetised state faster and recover quickly, was used reduce the pain of the mice. Isoflurane anaesthesia, is an inhalation general anesthesia, and the anesthesia-induction is stable, rapid, comfortable, fast recovery, good muscle relaxation, no sympathetic nervous system excitatory effect. In addition, isoflurane has a low metabolic rate in the liver, so it has little toxicity to the liver, and repeated use has no effect obvious side effects. Isoflurane was purchased from Reyward Life Technology Co., Ltd. (Shenzhen, China), and the concentration was MAC 1.6\%. After subcutaneous injection, the mice were sterilised with $75 \%$ medical alcohol. The mice were observed and weighed every 3 days, and the feeding conditions were strictly standardized. The volume of tumors was calculated as follows: $\mathrm{V}=$ (length $\times$ width2)/2. Before the tumors were collected, the isoflurane anaesthesia system was also used to reduce mice's pain, and then the mice were killed by cervical dislocation and the tumors were harvested. The bodies of mice were frozen at $-20{ }^{\circ} \mathrm{C}$ and then transferred to Laibite Biotech Inc. (Chongqing, China) for incineration.

For the lung metastasis model, mice were randomly divided into three groups. HGC-27 cells $\left(5 \times 10^{5} \mathrm{cells} / \mathrm{ml}\right)$ stably transfected with shGFP, shZC3H15-1 and shZC3H15-2 were injected subcutaneously into the tail vein of the mice in 18 November, 2019. Isoflurane anaesthesia system was used to reduce the mice's pain during this experiment. The mice were observed and weighed every 3 days. Before the lungs were collected, the isoflurane anaesthesia system was also used to reduce mice's pain, and then the mice were killed by cervical dislocation and the lungs were harvested. The bodies of mice 
were frozen at $-20^{\circ} \mathrm{C}$ and then transferred to Laibite Biotech Inc. (Chongqing, China) for incineration. The lungs were fixed with paraformaldehyde for H\&E staining.

\section{Transwell assay}

For the transwell assay, cells in serum-free MEM or RPMI-1640 Mediem were seeded into the 24-well Boyden chambers ( $8 \mu \mathrm{m}$ pore size, Corning). MEM or RPMI-1640 Mediem with $10 \%$ FBS was added to the lower chamber. Cells were fixed in $4 \%$ paraformaldehyde (PFA) and then stained with crystal violet. Then, Cells were imaged and calculated.

\section{Patient data analysis and patient tumor tissues}

Bioinformatics analyses were performed using these specific programs: TCGA (https://cancergenome.nih.gov), UCSC Xena (https:// xena.ucsc.edu/public/), starBase (https://www.starbase.sysu.edu.cn/), and Kaplan Meier-plotter (http://kmplot.com/analysis/). Clinical samples were obtained from Chaoying Biotechnology Co., Ltd. (Henan, China). All the studies were approved by the Medical Ethics Committee of Tongxu County People's Hospital of Henan Province. All of the patients were informed consent.

\section{Gene set enrichment analysis (GESA)}

To gain insight into ZC3H15 expression associated with the biological processes in GC, GSEA was performed using the Broad Institute GSEA version 4.0.3 software. The TCGA database was downloaded from UCSC Xena (https://xena.ucsc.edu/public/). The gene sets used for the enrichment analysis were downloaded from the Molecular Signatures Database (MsigDB, http://software.broadinstitute.org/gsea/index.jsp).

\section{Statistical analysis}

All experiments were performed at least three independent experiments, and the quantitative data were expressed as mean \pm SD. Two-tailed Student's t- test was performed to calculate significance, and a value of $P<0.05$ was considered statistically significant, ${ }^{*} P<0.05$, ${ }^{*} P<0.01,{ }^{\star} * \star * P<0.001$.

\section{Results}

\section{ZC3H15 is up-regulated in GC and high expression of ZC3H15 correlates with poor patient prognosis}


Overexpression of $\mathrm{ZC} 3 \mathrm{H} 15$ was found in 8 of 20 cancer types through Oncomine data-mining analysis (Fig. 1 A). In DErrico, Cho and Chen's dataset from Oncomine database, we found that expression of ZC3H15 mRNA was significantly increased from normal stomach tissues to gastric cancer tissues (Fig. 1 B-D). Then, we analyzed the expression data and survival information from the Gene Expression Omnibus (GEO) (GSE14210, GSE15459, and GSE22377), which was available from the Progression-free survival Kaplan-Meier database. We found that $\mathrm{ZC} 3 \mathrm{H} 15$ high expression was significantly correlated with poor survival of GC patients (Fig. $1 \mathrm{E}-\mathrm{G}$ ). To confirm the role of $\mathrm{ZC} 3 \mathrm{H} 15$ in $\mathrm{GC}$, we performed the univariate cox regression analyses based on the TCGA database and the results indicated that ZC3H15 expression was significantly correlated with age, depth of invasion, and histologic grade of gastric cancer (Table I). Moreover, multivariate cox regression analysis confirmed that age $(P=0.039)$, depth of invasion $(P=0.005)$, and histologic grade $(P=0.022)$ as independent prognostic factors for the overall survival of $\mathrm{GC}$ patients (Fig. $1 \mathrm{H}$ ). To confirm the role of $\mathrm{ZC} 3 \mathrm{H} 15$ in $\mathrm{GC}$, we performed immunohistochemistry analysis (IHC) using primary tissue samples from GC patients. The results demonstrated that ZC3H15 expression was significantly higher in GC tissues (Fig. $1 \mathrm{I}$ and $\mathrm{J}$ ). Then, we detected ZC3H15 expression at the mRNA and protein level in human GC cell lines and normal gastric epithelial cells (GES-1). We found that $\mathrm{ZC} 3 \mathrm{H} 15$ expression was commonly expressed in $\mathrm{GC}$ cell lines (Fig. $1 \mathrm{~K}$ ). Therefore, these data indicated that $\mathrm{ZC} 3 \mathrm{H} 15$ was upregulated in $\mathrm{GC}$ and high levels of $\mathrm{ZC} 3 \mathrm{H} 15$ was correlated with the poor prognosis of patients with GC.

\section{ZC3H15 is negatively regulated by miR-124-3p}

By using an online bioinformatics database (starBase, http://www.starbase.sysu.edu.cn/), miR-124-3p was identified as a putative miRNA targeting ZC3H15. Downregulation of miR-124-3p was found in gastric cancer compared with normal stomach tissues (Fig. 2 A). And MTT assays demonstrated that miR-124-3p inhibited cell proliferation in HGC-27 cells (Fig. 2 B). By analysis of the data from the starBase database, we found that miR-124-3p expression was negatively correlated with ZC3H15 expression ( $R=-0.135, P=9.00 e-03$ ) (Fig. 2 C). Then, miR-124-3p mimic, miR-124-3p inhibitor or control miRNA was then transfected into HGC-27 and MKN-45 cells to evaluate the influence of miR-124-3p on the ZC3H15 expression. Transfection with miR-124-3p mimics significantly decreased ZC3H15 mRNA and protein expression in GC cells. In contrast, miR-124-3p inhibitor increased ZC3H15 expression in the cells (Fig. $2 \mathrm{D}$ and E). By analysis of starBase database, we found that miR-124-3p has a seed region contains 6 nucleotides that match the $3^{\prime} \mathrm{UTR}$ of human $\mathrm{ZC} 3 \mathrm{H} 15$. To verify whether $\mathrm{ZC} 3 \mathrm{H} 15$ is a direct target of miR-124-3p, we constructed luciferase reporter plasmids carrying wild-type ZC3H15 3'-UTR or mutant ZC3H15 3'-UTR and then transfected 293FT cells together with miR-124-3p mimics or control. The relative luciferase activity of the reporter was inhibited by the mimics; however, there was no significant change in the luciferase activity of mutagenesis reporter (Fig. $2 \mathrm{~F}$ ). Taken together, these data indicate that miR-124-3p reduces ZC3H15 expression by directly targeting the 3'-UTR of ZC3H15 mRNA. 


\section{ZC3H15 promotes cell proliferation, migration, and invasion in vitro}

To investigate the biological function of $\mathrm{ZC} 3 \mathrm{H} 15$ in GC cells, we established stably transfected ZC3H15knockdown and $\mathrm{ZC} 3 \mathrm{H} 15$-overexpressing cells for further investigation. Western blot and RT-PCR analysis was conducted to confirm the efficiency of the knockdown and overexpression system (Fig. 3 A). GESA using TCGA datasets showed positive association with cell cycle and metastasis in ZC3H15 high expression GC (Fig. $3 \mathrm{~B}$ and C). Then, MTT and BrdU assays demonstrated that silencing of ZC3H15 in HGC-27 cells significantly inhibited cell proliferation (Fig. 3 D and Fig-S1). Conversely, ectopic ZC3H15 overexpression enhanced cell proliferation in MKN-45 cells (Fig. $3 \mathrm{E}$ ). In addition, ZC3H15 increased the colony formation of GC cells (Fig. $3 \mathrm{~F}$ and $\mathrm{G}$ ). Then, the transwell assays were performed and the results demonstrated that $\mathrm{ZC} 3 \mathrm{H} 15$ knockdown in $\mathrm{HGC}-27$ cells dramatically suppressed cell migration and invasion (Fig. $3 \mathrm{H}$ ). However, the metastatic effect was significantly elevated in ZC3H15-overexpressing MKN-45 cells (Fig. $3 \mathrm{I}$ ). Therefore, these results indicated that $\mathrm{ZC} 3 \mathrm{H} 15$ accelerates cell proliferation, migration, and invasion of GC cells in vitro.

\section{ZC3H15 promotes tumor growth and lung metastasis in vivo}

To investigate the role of $\mathrm{ZC} 3 \mathrm{H} 15$ in tumor growth of $\mathrm{GC}$ cells, we performed the subcutaneous xenograft experiment and then found that $\mathrm{ZC} 3 \mathrm{H} 15$ knockdown significantly retarded the tumor growth of $\mathrm{GC}$ cells (Fig. $4 \mathrm{~A}$ and B). Immunohistochemical staining revealed that expression $\mathrm{ZC} 3 \mathrm{H} 15$ was dramatically reduced in the $\mathrm{ZC} 3 \mathrm{H} 15-k n o c k d o w n$ tumors, and the expression of Ki-67 was also decreased in the shZC3H15 tumors (Fig. 4 C). To determine whether ZC3H15 influences GC metastasis in vivo, the lung metastasis models were used to evaluate the metastatic effect of $\mathrm{ZC} 3 \mathrm{H} 15$. The number and size of lung nodules was significantly reduced by ZC3H15 knockdown in HGC-27 cells (Fig. 4 D). Taken together, these results demonstrated that $\mathrm{ZC} 3 \mathrm{H} 15$ promotes tumor growth and lung metastasis of GC cells in vivo.

\section{ZC3H15 stabilizes c-Myc by mediating its ubiquitination degradation}

To further confirm the effect of $\mathrm{ZC} 3 \mathrm{H} 15$ on GC cells, some proteins linked to cell proliferation and metastasis were analyzed by western blot. We found that silencing of $\mathrm{ZC} 3 \mathrm{H} 15$ significantly decreased the protein levels of c-Myc, CyclinD1, CDK4, CDK6, MMP7, and N-cadherin of HGC-27 cells. In addition, overexpression of $\mathrm{ZC} 3 \mathrm{H} 15$ in MKN-45 cells could increase the protein levels of these proteins (Fig. $5 \mathrm{~A}$ ). Interestingly, quantitative PCR analysis revealed that downregulation of ZC3H15 slightly reduced c-Myc mRNA levels, suggesting that ZC3H15 may regulate c-Myc levels post-transcriptionally (Fig. $5 \mathrm{~B}$ ). To further confirm that ZC3H15 modulates c-Myc ubiquitination, ZC3H15-knockdown HGC-27 cells were 
treated with the proteasome inhibitor MG-132, and the results demonstrated that c-Myc downregulation could be rescued by MG-132 (Fig. 5 C). We then examined the turnover rate of c-Myc, and we found that silencing of ZC3H15 in HGC-27 cells significantly increased the turnover rate of c-Myc (Fig. 5 D). Conversely, $\mathrm{ZC} 3 \mathrm{H} 15$ overexpression could reduce the turnover rate of c-Myc (Fig. $5 \mathrm{E}$ ). Moreover, the ubiquitination of c-Myc was detected by the ubiquitination assay, and the results indicated that upregulation of $\mathrm{ZC} 3 \mathrm{H} 15$ could reduce the ubiquitination levels of c-Myc (Fig. $5 \mathrm{~F}$ ). Then, we examine and confirm the relationship between $\mathrm{ZC} 3 \mathrm{H} 15$ and c-Myc in human cancers, we performed IHC staining on clinical tumor tissues of GC patients to assess the expression of $\mathrm{ZC} 3 \mathrm{H} 15$ and c-Myc. The results demonstrated that $\mathrm{ZC} 3 \mathrm{H} 15$ and c-Myc showed a significant positive correlation in staining intensity (FigS2). Taken together, these data suggested that $\mathrm{ZC} 3 \mathrm{H} 15$ regulated the stability of $\mathrm{c}-\mathrm{Myc}$ through reduction of c-Myc ubiquitination degradation.

\section{ZC3H15 directly inhibits the transcription of FBXW7 in GC cells}

FBXW7 is an important tumor suppressor, and is responsible for the ubiquitylation and proteasomal degradation of c-Myc. ZC3H15 is a classical $\mathrm{CCCH}$-type zinc finger protein, suggesting it may be function as a transcription factor role in cell signaling. Thus, we speculated that $\mathrm{ZC} 3 \mathrm{H} 15$ might modulate the protein stability of c-Myc by targeting FBXW7. Then, we performed quantitative PCR and western blot analysis and found that the mRNA and protein expression levels of FBXW7 were negatively correlated with ZC3H15 in HGC-27 and MKN-45 cells (Fig. $6 \mathrm{~A}$ and B). Then, we performed the dual-luciferase reporter assay found that FBXW7 promoter activity was significantly enhanced in ZC3H15-knockdown cells and was reduced in $\mathrm{ZC} 3 \mathrm{H} 15$-overexpressing cells, indicating that the promoter activity of FBXW7 was inhibited by $\mathrm{ZC} 3 \mathrm{H} 15$ (Fig. $6 \mathrm{C}$ ). To further determine whether ZC3H15 bind the promoter of FBXW7, we performed the ChIP assay and found that ZC3H15 bind the region P3 (-1020 to -804 bp) of FBXW7 promoter (Fig. 6 D). These data indicated that ZC3H15 could suppress FBXW7 transcription.

\section{Downregulation of FBXW7 in ZC3H15-knockdown cells abrogates the effects induced by ZC3H15 silencing}

To further confirm that $\mathrm{ZC} 3 \mathrm{H} 15$ regulates the ubiquitination degradation of c-Myc by targeting FBXW7. We knockdown FBXW7 expression with the highly effective shFBXW7\#2 in ZC3H15-knockdown HGC-27 cells, and found that c-Myc expression was increased after FBXW7 knockdown in ZC3H15-knockdown cells (Fig. $7 \mathrm{~A}$ and Fig. S3). MTT assays were performed and indicated that the cell proliferation of ZC3H15-knockdown cells were clearly increased after FBXW7-knockdown treatment (Fig. 7B). In addition, silencing of FBXW7 also could promote cell migration and invasion of ZC3H15-knockdown cells (Fig. 7 C). These data demonstrated that the ZC3H15-FBXW7-c-Myc axis might play a critical role in the cell proliferation and tumorigenesis of GC cells (Fig. $7 \mathrm{D}$ ). 


\section{Discussion}

GC exhibits the high rates of proliferation and metastasis, is a seriously threatens for human health. Gastrectomy is currently considered to be the mainstay radical treatments. If the tumor is detected and treated in early diagnosis, the 5-year survival rate of GC can reach $90 \%$ [37]. However, the overall survival is extremely poor, with an average 5 -year survival rate of less than $20 \%$ [38]. Therefore, a better understanding of the relationships between cancerogenesis, development and prognosis will help to improve the diagnosis and treatment of GC. $\mathrm{ZC} 3 \mathrm{H} 15$, a highly conserved eukaryotic protein widely expressed in various normal human tissues, contains a DFRP domain and two $\mathrm{CCCH}$-type zinc finger domains. DFRP domain was responsible for interacting with DRG1 and then blocking the polyubiquitination and degradation of DRG1. In addition, ZC3H15 is also a classical CCCH-type zinc finger protein, suggesting it may function as a putative transcription factor role in cell signaling. To date, dysregulation of ZC3H15 has been reported in HCC and AML. However, the biological roles of ZC3H15 in $\mathrm{GC}$ remain unclear.

In the present study, we found that $\mathrm{ZC} 3 \mathrm{H} 15$ was up-regulated in the patients with $\mathrm{GC}$ according to the immunohistochemistry and western blot analysis. Moreover, we observed that silencing of $\mathrm{ZC} 3 \mathrm{H} 15$ inhibited cell proliferation, metastasis, and tumorigenesis of GC cells, and ZC3H15 overexpression could accelerate these progressions. These data suggest that $\mathrm{ZC} 3 \mathrm{H} 15$ plays as an oncogene in $\mathrm{GC}$ cells.

The biological mechanism of $\mathrm{ZC} 3 \mathrm{H} 15$ in human cancers remains largely unclear. Bei et al. used a microarray to evaluate the functional role of $\mathrm{ZC} 3 \mathrm{H} 15$, and they found that $\mathrm{ZC} 3 \mathrm{H} 15$ was involved in several critical signaling pathways, such as WNT pathway, NF-KB pathway, EGF pathway, TGF- $\beta$ pathway, and PDGF pathway [18]. Here, we demonstrated that silencing of $\mathrm{ZC} 3 \mathrm{H} 15$ reduced the protein expression levels of c-Myc and its downstream molecules such as CDK4, CDK6, and CyclinD1 in GC cells. However, CMyc was not obviously changed at the mRNA level in $\mathrm{ZC} 3 \mathrm{H} 15$-silencing GC cells. Subsequently, we performed the ubiquitination assay and turnover assay and found that $\mathrm{ZC} 3 \mathrm{H} 15$ positively regulated cMyc protein levels through reducing c-Myc degradation. We then found that the mRNA expression of FBXW7, a well-known E3 ubiquitin ligase of c-Myc, was significantly elevated in ZC3H15-knockdown GC cells. In addition, we performed the Dual-luciferase reporter assay and ChIP assay, and found that ZC3H15 could inhibit the transcription of FBXW7 by binding to the promoter-proximal region P3 of FBXW7 promoter.

There are few studies about the mechanism in regulation of $\mathrm{ZC} 3 \mathrm{H} 15$ expression. To identify the mechanism in the up-regulation of $\mathrm{ZC} 3 \mathrm{H} 15$ in GC, we put the focus on miRNAs. Based on bioinformatics analysis, ZC3H15 is a predicted target of miR-124-3p. miR-124-3p has been proven to be a tumor suppressor in gastric cancer progression [34]. We found that overexpression of miR-124-3p inhibited the expression of $\mathrm{ZC} 3 \mathrm{H} 15$, and further revealed that miR-124-3p degraded $\mathrm{ZC} 3 \mathrm{H} 15$ by directly targeting its 3'UTR.

In conclusion, our results demonstrated that $\mathrm{ZC} 3 \mathrm{H} 15$ promoted cell proliferation, migration, invasion, and tumorigenesis of GC cells, and this function was associated with transcriptional repression of FBXW7, 
which was responsible for the ubiquitination and degradation of c-Myc. Additionally, our data revealed that ZC3H15 was directly target of miR-124-3p in GC. These results provide new insights into the functions of $\mathrm{ZC} 3 \mathrm{H} 15$ and suggest that miR-124-3p/ZC3H15 may be a potential target for the treatment of GC.

\section{Abbreviations}

ZC3H15, Zinc finger CCCH-type containing 15; FBXW7, F-Box And WD Repeat Domain Containing 7; GC, Gastric cancer; HCC, hepatocellular carcinoma; AML, acute myeloid leukemia; LEREPO4, likely ortholog of mouse immediate early response erythropoietin 4; miRNAs, microRNAs; IHC, immunohistochemistry analysis; $\mathrm{CHX}$, cycloheximide; DFRP, DRG family regulatory protein.

\section{Declarations}

\section{Acknowledgements}

We are particularly grateful to Guanghui Zhang, Yanli Zhang and Xiaosong Hu, and we also thank all the members of our laboratory for helpful discussion.

\section{Authors' contributions}

$\mathrm{JH}, \mathrm{YL}, \mathrm{DY}, \mathrm{PH}, \mathrm{ZW}, \mathrm{HG}, \mathrm{CL}, \mathrm{SG}$, and $\mathrm{HC}$ have participated in investigation, methodology and validation of data presented in this article. $\mathrm{JH}$ and $\mathrm{HC}$ are responsible of Formal Analysis of data. $\mathrm{JH}$ and $\mathrm{YL}$ wrote and edited this manuscript, and $\mathrm{HC}$ read and revised this manuscript.

\section{Funding information}

This work was supported by the National Key Research and Development Program of China (2016YFC1302204 and 2017YFC1308600), the Natural Science Foundation of Chongqing (No. cstc2019jcyj-zdxmX0033), the National Natural Science Foundation of China (81872071, 81672502, and 81972357) and the Fundamental Research Funds for the Central Universities (SWU118097).

\section{Availability of data and materials}

All of the data and material in this paper are available when requested

\section{Ethics approval and consent to participate}


All experiments involving cancer patients samples were obtained from Chaoying Biotechnology Co., Ltd. (Henan, China), and the studies were approved by the Medical Ethics Committee of Tongxu County People's Hospital of Henan Province. All of the patients were informed consent. Animal welfare and experimental procedures were carried out in accordance with the Guide for the Care and Use of Laboratory Animals and approved by the animal ethics committee of Southwest University.

\section{Consent for publication}

Not applicable

\section{Competing interests}

The authors declare that they have no conflict of interest.

\section{Reference}

1. T. Hamamoto, H. Yokozaki, S. Semba, W. Yasui, S. Yunotani, K. Miyazaki, et al.: Altered microsatellites in incomplete-type intestinal metaplasia adjacent to primary gastric cancers. $J$ Clin Pathol 1997, 10(50): 841-846.

2. A. Jemal, F. Bray, M.M. Center, J. Ferlay, E. Ward, D. Forman: Global cancer statistics. CA Cancer J Clin 2011, 2(61): 69-90.

3. P.A. Leake, R. Cardoso, R. Seevaratnam, L. Lourenco, L. Helyer, A. Mahar, et al.: A systematic review of the accuracy and indications for diagnostic laparoscopy prior to curative-intent resection of gastric cancer. Gastric Cancer 2012, 15 Suppl 1): S38-47.

4. D.E. Guggenheim, M.A. Shah: Gastric cancer epidemiology and risk factors. J Surg Oncol 2013, 3(107): 230-236.

5. A.G. Clark, D.M. Vignjevic: Modes of cancer cell invasion and the role of the microenvironment. Curr Opin Cell Biol 2015, 36): 13-22.

6. L.E. Wroblewski, R.M. Peek, Jr.: Helicobacter pylori, Cancer, and the Gastric Microbiota. Adv Exp Med Biol 2016, 908): 393-408.

7. Y. Xuan, Y. Wang: Long non-coding RNA SNHG3 promotes progression of gastric cancer by regulating neighboring MED18 gene methylation. Cell Death Dis 2019, 10(10): 694.

8. A.M. Kappas, M. Fatouros, D.H. Roukos: Is it time to change surgical strategy for gastric cancer in the United States? Ann Surg Oncol 2004, 8(11): 727-730.

9. R.C. Gregory, K.A. Lord, L.B. Panek, P. Gaines, S.B. Dillon, D.M. Wojchowski: Subtraction cloning and initial characterization of novel epo-immediate response genes. Cytokine 2000, 7(12): 845-857.

10. R.L. Strausberg, E.A. Feingold, L.H. Grouse, J.G. Derge, R.D. Klausner, F.S. Collins, et al.: Generation and initial analysis of more than 15,000 full-length human and mouse cDNA sequences. Proc Nat/ 
Acad Sci U S A 2002, 26(99): 16899-16903.

11. G. Capalbo, T. Muller-Kuller, U. Dietrich, D. Hoelzer, O.G. Ottmann, U.J. Scheuring: Inhibition of X4tropic HIV type 1 replication by knockdown of the cellular protein LEREP04. AIDS Res Hum Retroviruses 2010, 10(26): 1155-1161.

12. K. Ishikawa, S. Azuma, S. Ikawa, K. Semba, J. Inoue: Identification of DRG family regulatory proteins (DFRPs): specific regulation of DRG1 and DRG2. Genes Cells 2005, 2(10): 139-150.

13. G. Capalbo, T. Mueller-Kuller, S. Koschmieder, H.U. Klein, O.G. Ottmann, D. Hoelzer, et al.: Characterization of ZC3H15 as a potential TRAF-2-interacting protein implicated in the NFkappaB pathway and overexpressed in AML. Int J Oncol 2013, 1(43): 246-254.

14. J.R. Bradley, J.S. Pober: Tumor necrosis factor receptor-associated factors (TRAFs). Oncogene 2001, 44(20): 6482-6491.

15. P.W. Dempsey, S.E. Doyle, J.Q. He, G. Cheng: The signaling adaptors and pathways activated by TNF superfamily. Cytokine Growth Factor Rev 2003, 3-4(14): 193-209.

16. J. Schulze-Luehrmann, S. Ghosh: Antigen-receptor signaling to nuclear factor kappa B. Immunity 2006, 5(25): 701-715.

17. C. Bubici, S. Papa, K. Dean, G. Franzoso: Mutual cross-talk between reactive oxygen species and nuclear factor-kappa B: molecular basis and biological significance. Oncogene 2006, 51(25): 67316748.

18. B.G. Jiang, Z.H. Wan, J. Huang, L.M. Li, H. Liu, S.Y. Fu, et al.: Elevated ZC3H15 increases HCC growth and predicts poor survival after surgical resection. Oncotarget 2016, 24(7): 37238-37249.

19. A. Albihn, J.I. Johnsen, M.A. Henriksson: MYC in oncogenesis and as a target for cancer therapies. Adv Cancer Res 2010, 107): 163-224.

20. C.V. Dang: MYC on the path to cancer. Cell 2012, 1(149): 22-35.

21. H.J. Chung, D. Levens: c-myc expression: keep the noise down! Mol Cells 2005, 2(20): 157-166.

22. C.H. Yeh, M. Bellon, C. Nicot: FBXW7: a critical tumor suppressor of human cancers. Mol Cancer 2018, 1(17): 115.

23. J. Cao, M.H. Ge, Z.Q. Ling: Fbxw7 Tumor Suppressor: A Vital Regulator Contributes to Human Tumorigenesis. Medicine (Baltimore) 2016, 7(95): e2496.

24. S. Akhoondi, D. Sun, N. von der Lehr, S. Apostolidou, K. Klotz, A. Maljukova, et al.: FBXW7/hCDC4 is a general tumor suppressor in human cancer. Cancer Res 2007, 19(67): 9006-9012.

25. B. King, T. Trimarchi, L. Reavie, L. Xu, J. Mullenders, P. Ntziachristos, et al.: The ubiquitin ligase FBXW7 modulates leukemia-initiating cell activity by regulating MYC stability. Cel/ 2013, 7(153): 1552-1566.

26. A. Vishnoi, S. Rani: MiRNA Biogenesis and Regulation of Diseases: An Overview. Methods Mol Biol 2017, 1509): 1-10.

27. J.C. Chuang, P.A. Jones: Epigenetics and microRNAs. Pediatr Res 2007, 5 Pt 2(61): 24R-29R. 
28. Q. Wu, Z. Yang, Y. Shi, D. Fan: MiRNAs in human cancers: the diagnostic and therapeutic implications. Curr Pharm Des 2014, 33(20): 5336-5347.

29. L. Tutar, E. Tutar, Y. Tutar: MicroRNAs and cancer, an overview. Curr Pharm Biotechno/2014, 5(15): 430-437.

30. L. Tutar, E. Tutar, A. Ozgur, Y. Tutar: Therapeutic Targeting of microRNAs in Cancer: Future Perspectives. Drug Dev Res 2015, 7(76): 382-388.

31. Y. Wang, L. Chen, Z. Wu, M. Wang, F. Jin, N. Wang, et al.: miR-124-3p functions as a tumor suppressor in breast cancer by targeting CBL. BMC Cancer 2016, 1(16): 826.

32. P. Wang, L. Zhang, J. Zhang, G. Xu: MicroRNA-124-3p inhibits cell growth and metastasis in cervical cancer by targeting IGF2BP1. Exp Ther Med 2018, 2(15): 1385-1393.

33. J.R. Wang, B. Liu, L. Zhou, Y.X. Huang: MicroRNA-124-3p suppresses cell migration and invasion by targeting ITGA3 signaling in bladder cancer. Cancer Biomark 2019, 2(24): 159-172.

34. F. Liu, H. Hu, J. Zhao, Z. Zhang, X. Ai, L. Tang, et al.: miR-124-3p acts as a potential marker and suppresses tumor growth in gastric cancer. Biomed Rep 2018, 2(9): 147-155.

35. J. Hou, Q. Deng, J. Zhou, J. Zou, Y. Zhang, P. Tan, et al.: CSN6 controls the proliferation and metastasis of glioblastoma by CHIP-mediated degradation of EGFR. Oncogene 2017, 8(36): 11341144.

36. J. Hou, A. Lv, Q. Deng, G. Zhang, X. Hu, H. Cui: TROP2 promotes the proliferation and metastasis of glioblastoma cells by activating the JAK2/STAT3 signaling pathway. Oncol Rep 2019, 2(41): 753764.

37. R. Miyahara, Y. Niwa, T. Matsuura, O. Maeda, T. Ando, N. Ohmiya, et al.: Prevalence and prognosis of gastric cancer detected by screening in a large Japanese population: data from a single institute over 30 years. J Gastroenterol Hepatol 2007, 9(22): 1435-1442.

38. Z. Song, Y. Wu, J. Yang, D. Yang, X. Fang: Progress in the treatment of advanced gastric cancer. Tumour Biol 2017, 7(39): 1010428317714626.

\section{Tables}


Table I.

Correlation of $\mathrm{ZC} 3 \mathrm{H} 15$ expression with clinicpathological variables in TGGA data sets

\begin{tabular}{|c|c|c|c|c|c|c|c|c|}
\hline \multicolumn{2}{|c|}{ Clinicopathological features } & \multirow[t]{2}{*}{ Cases } & \multicolumn{4}{|c|}{ ZC3H15 expression } & \multirow[t]{2}{*}{$F$} & \multirow[t]{2}{*}{$P$} \\
\hline & & & Low & $\%$ & High & $\%$ & & \\
\hline \multirow[t]{2}{*}{ Age } & $<60$ & 134 & 79 & 59.0 & 55 & 41.0 & \multirow[t]{2}{*}{8.009} & \multirow[t]{2}{*}{0.005} \\
\hline & $\geq 60$ & 278 & 119 & 42.8 & 159 & 57.2 & & \\
\hline \multirow[t]{2}{*}{ Gender } & Male & 273 & 135 & 49.5 & 138 & 50.5 & \multirow[t]{2}{*}{2.042} & \multirow[t]{2}{*}{0.154} \\
\hline & Female & 144 & 66 & 45.8 & 78 & 54.2 & & \\
\hline \multirow[t]{2}{*}{ H. pylori infection } & Negative & 164 & 56 & 34.1 & 108 & 65.9 & \multirow[t]{2}{*}{0.499} & \multirow[t]{2}{*}{0.481} \\
\hline & Positive & 21 & 10 & 47.6 & 11 & 52.4 & & \\
\hline \multirow[t]{4}{*}{ Depth of invasion } & T1 & 24 & 10 & 41.7 & 14 & 58.3 & \multirow[t]{4}{*}{3.207} & \multirow[t]{4}{*}{0.023} \\
\hline & $\mathrm{T} 2$ & 90 & 54 & 60.0 & 36 & 40.0 & & \\
\hline & T3 & 189 & 86 & 45.5 & 103 & 54.5 & & \\
\hline & $\mathrm{T} 4$ & 111 & 51 & 46.0 & 60 & 54.0 & & \\
\hline \multirow[t]{4}{*}{ Lymph node metastasis } & No & 130 & 66 & 50.8 & 64 & 49.2 & \multirow[t]{4}{*}{0.935} & \multirow[t]{4}{*}{0.424} \\
\hline & $\mathrm{N} 1$ & 114 & 55 & 48.2 & 59 & 51.8 & & \\
\hline & N2 & 86 & 38 & 44.2 & 48 & 55.8 & & \\
\hline & N3 & 77 & 39 & 50.6 & 38 & 49.4 & & \\
\hline \multirow[t]{2}{*}{ Distant metastasis } & MO & 374 & 178 & 47.6 & 196 & 52.4 & \multirow[t]{2}{*}{0.294} & \multirow[t]{2}{*}{0.588} \\
\hline & M1 & 22 & 14 & 63.6 & 8 & 36.4 & & \\
\hline \multirow[t]{3}{*}{ Histologic Grade } & G1 & 10 & 5 & 50.0 & 5 & 50.0 & \multirow[t]{3}{*}{4.042} & \multirow[t]{3}{*}{0.018} \\
\hline & $\mathrm{G} 2$ & 153 & 61 & 39.9 & 92 & 40.1 & & \\
\hline & G3 & 245 & 131 & 53.5 & 114 & 46.5 & & \\
\hline \multirow[t]{4}{*}{ Grade } & Stage I & 58 & 31 & 53.4 & 27 & 46.6 & \multirow[t]{4}{*}{1.738} & \multirow[t]{4}{*}{0.159} \\
\hline & Stage II & 138 & 71 & 51.4 & 67 & 48.6 & & \\
\hline & Stage III & 174 & 75 & 43.1 & 99 & 56.9 & & \\
\hline & Stage IV & 34 & 19 & 55.9 & 15 & 44.1 & & \\
\hline
\end{tabular}

Table II. 
Primer pairs for real-time PCR:

\begin{tabular}{|ll|}
\hline ZC3H15-F & AACAAAATCCACGTCAGGTAGC \\
\hline ZC3H15-R & TGCACATACTACAGACTTGGGA \\
\hline c-Myc-F & GTCAAGAGGCGAACACACAAC \\
\hline c-Myc-R & TTGGACGGACAGGATGTATGC \\
\hline CyclinD1-F & GCTGCGAAGTGGAAACCATC \\
\hline CyclinD1-R & CCTCCTTCTGCACACATTTGAA \\
\hline CDK4-F & ATGGCTACCTCTCGATATGAGC \\
\hline CDK4-R & CATTGGGGACTCTCACACTCT \\
\hline CDK6-F & CCAGATGGCTCTAACCTCAGT \\
\hline CDK6-R & AACTTCCACGAAAAAGAGGCTT \\
\hline MMP7-F & GAGTGAGCTACAGTGGGAACA \\
\hline MMP7-R & CTATGACGCGGGAGTTTAACAT \\
\hline N-cadherin-F & AGCCAACCTTAACTGAGGAGT \\
\hline N-cadherin-R & GGCAAGTTGATTGGAGGGATG \\
\hline FBXW7-F & TAGAACCCCAGTTTCAACGAGA \\
\hline FBXW7-R & GCCAACTCTTTAGGGAGCAAT \\
\hline GAPDH-F & GGAGCGAGATCCCTCCAAAAT \\
\hline GAPDH-R & GGCTGTTGTCATACTTCTCATGG \\
\hline
\end{tabular}

Primer pairs for ChIP assays: 


\begin{tabular}{|ll|}
\hline FBXW7-1/-436-F & GTGCATAGATTGCCTTCCCAG \\
\hline FBXW7-1/-436-R & CCATTCACAGTGCTCAATCAACTAT \\
\hline FBXW7-372/-607-F & GACTGGCTGTTGGAAGAAGAAAATA \\
\hline FBXW7-372/-607-R & ACGGCCTAAGATAAAGTCTGGAGAT \\
\hline FBXW7-562/-835-F & GCCACTTTGAAGAGAGTCTTCATCT \\
\hline FBXW7-562/-835-R & AAGCATAACAGTCACCCAACTGATT \\
\hline FBXW7-804/-1020-F & TGTCTTTAATCAGTTGGGTGACTGT \\
\hline FBXW7-804/-1020-R & ATGAGCACTATTTTCAAGTGTGTGC \\
\hline FBXW7-1001/-1399-F & GAGAGCACACACTTGAAAATAGTGC \\
\hline FBXW7-1001/-1399-R & AGTAATGTGAACACAACCAAAGCAG \\
\hline FBXW7-1294/-1620-F & CTCCTCTTGGTTGACGAATACTCTC \\
\hline FBXW7-1294/-1620-R & CTATGACGCGGGAGTTTAACAT \\
\hline
\end{tabular}

Figures 


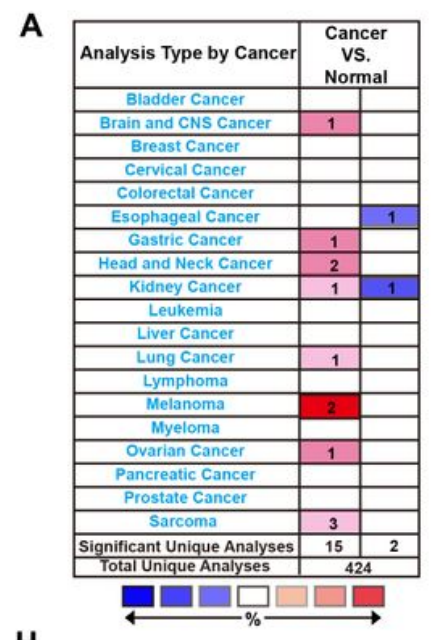

H

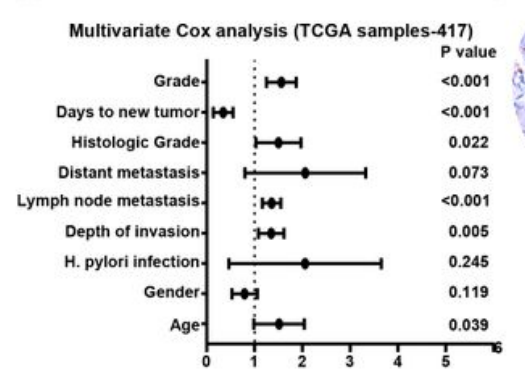

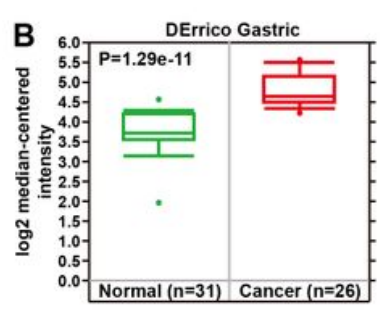
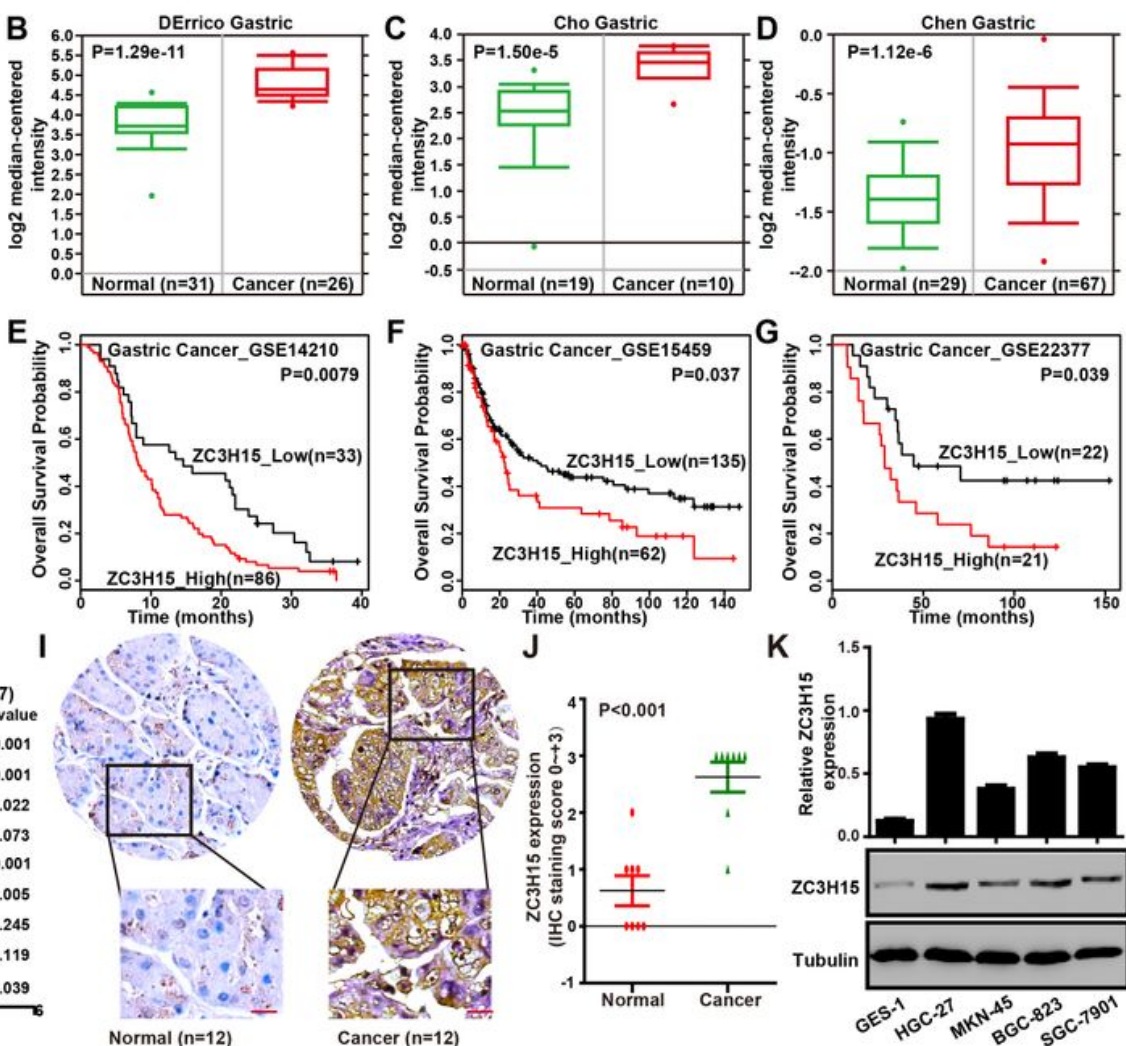

$\mathrm{J}$

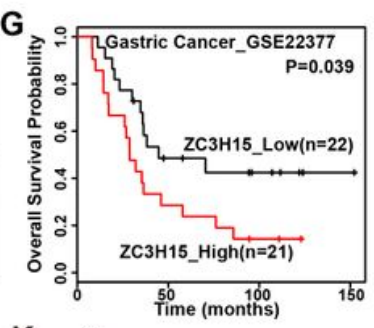

K

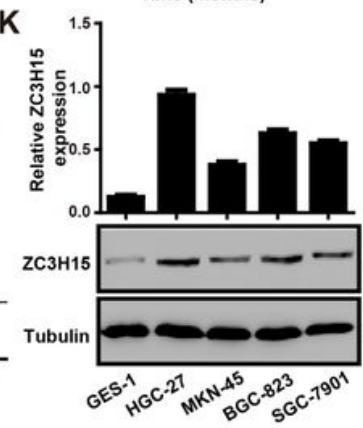

\section{Figure 1}

$\mathrm{ZC} 3 \mathrm{H} 15$ is up-regulated in $\mathrm{GC}$ and high expression of $\mathrm{ZC} 3 \mathrm{H} 15$ correlates with poor patient prognosis $(\mathrm{A})$ Up-regulation of ZC3H15 was found in 8 of 20 cancer types. (B-D) Level of ZC3H15 mRNA was significantly increased from normal stomach tissues to gastric cancer tissues in DErrico, Cho, and Chen dataset. (E-G) Kaplan-Meier analysis of overall survival using data from the GSE14210, GSE15459, GSE22377 database and $P$ values were indicated. $(H)$ Multivariate cox regression analysis of independent predictors of the overall survival of patients with gastric cancer. $(I, J)$ Immunohistochemical analyses of $\mathrm{ZC} 3 \mathrm{H} 15$ expression in 12 paired samples of gastric cancer and normal stomach tissue, $\mathrm{P}<0.001$. (K) Western blot and and RT-PCR analyses were used to examine ZC3H15 expression in GES1 cells and gastric cancer cell lines. 

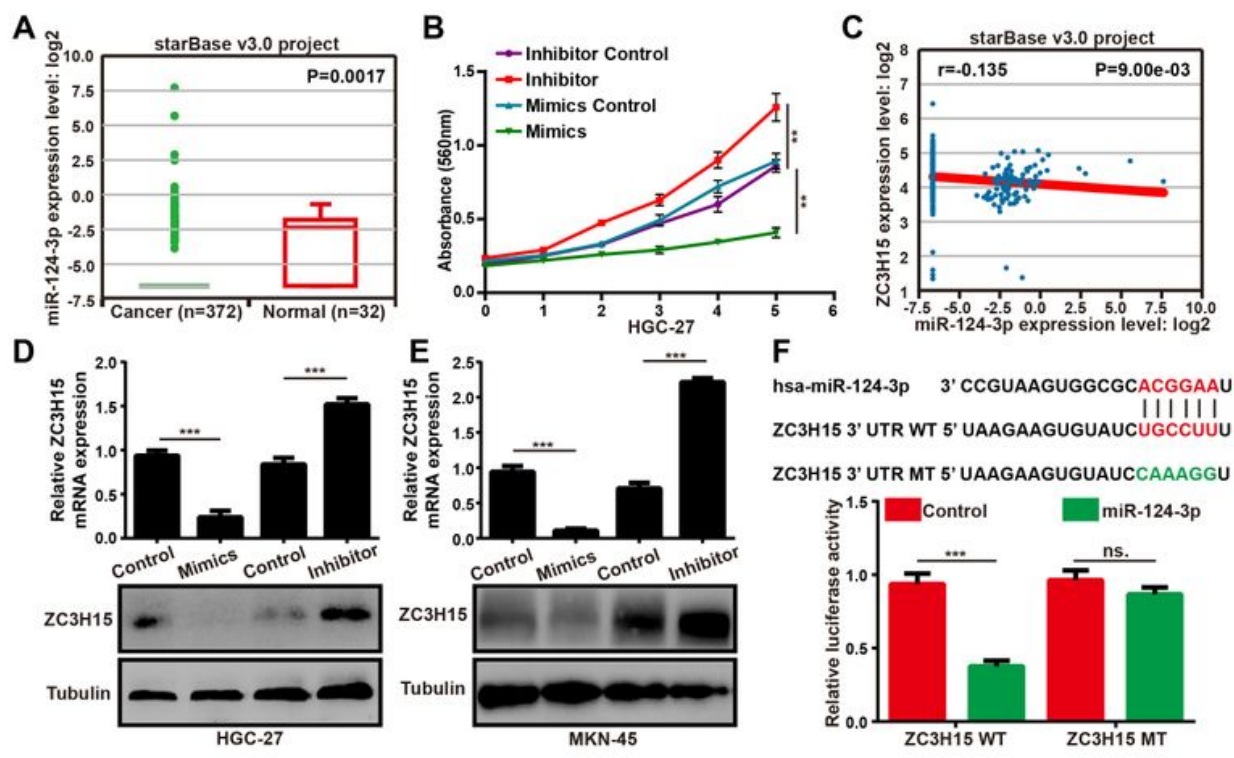

hsa-miR-124-3p 3' CCGUAAGUGGCGCACGGAAU

ZC3H15 3, UTR WT 5' UAAGAAGUGUAUCUGCCUUU

ZC3H15 3' UTR MT 5' UAAGAAGUGUAUCCAAAGGU

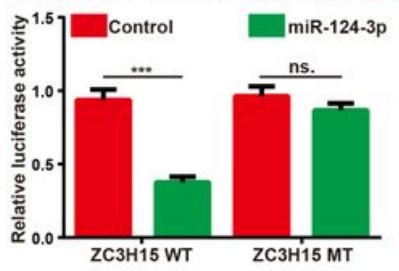

\section{Figure 2}

ZC3H15 is negatively regulated by miR-124-3p (A) Box plot of miR-124-3p expression levels in the gastric cancer tissues and normal stomach tissues in the starBase data set with the log-rank test P-values indicated. (B) MTT assays were performed to assess the effect of miR miR-124-3p mimic, miR-124-3p inhibitor or control miRNA on cell proliferation of HGC-27 cells. (C) Correlation of the level of miR-124 mRNA expression with ZC3H15 in the starBase data set. Results indicated a negative correlation between miR-124 and ZC3H15 expression. $P=9.00 \mathrm{e}-03, \mathrm{R}=-0.135$. (D, E) HGC-27 and MKN-45 cells were transfected with miR-124-3p mimic, miR-124-3p inhibitor or control miRNA and then subjected to western blot. (F) ZC3H15 3' UTR contains predicted miR-124-3p binding site and the alignment of the seed region of miR124-3p with ZC3H15 3' UTR is shown. 293FT cells were transfected with miR-124-3p mimics or Control together with luciferase constructs containing a wild-type or mutated ZC3H15 3' UTR, and luciferase activity was evaluated 36 hours later. 

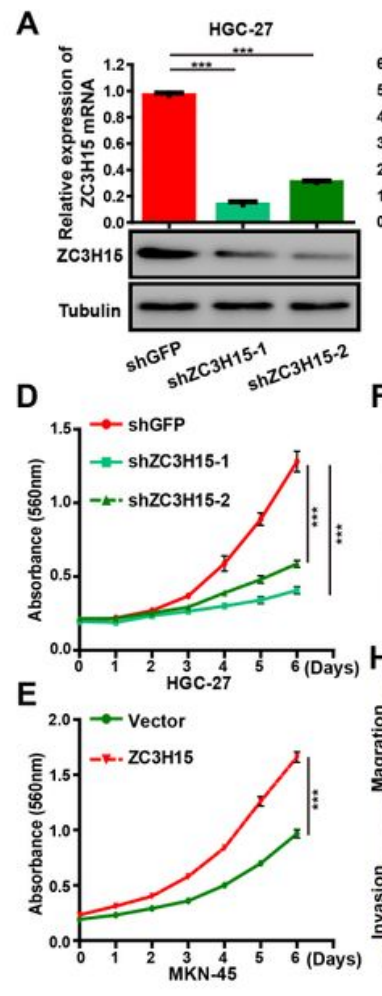

B
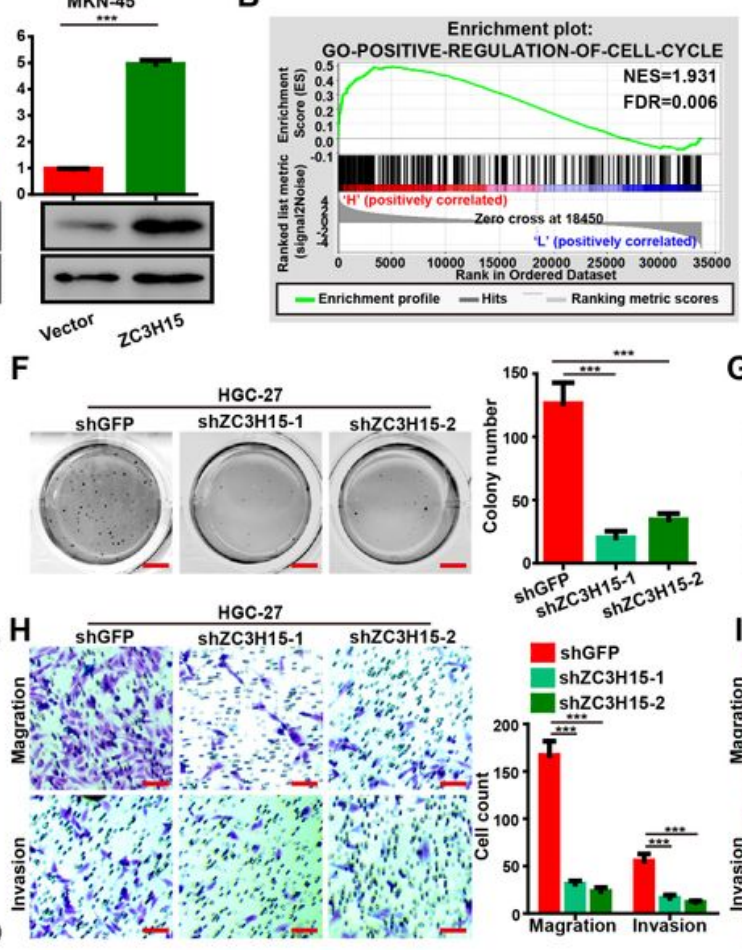

C

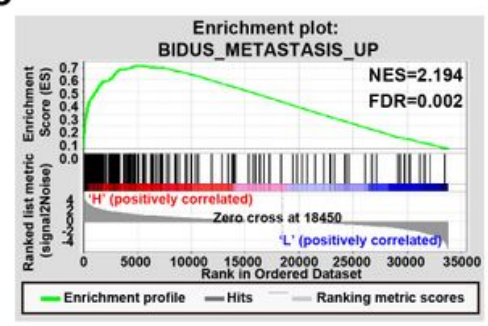

G
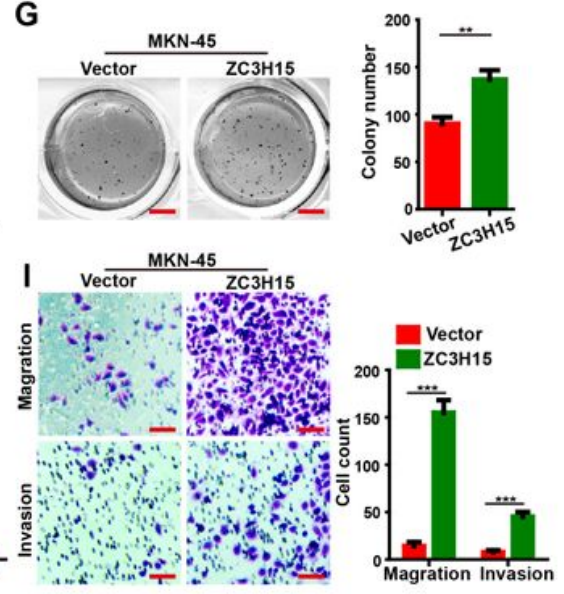

\section{Figure 3}

$\mathrm{ZC} 3 \mathrm{H} 15$ promotes cell proliferation, migration, and invasion in vitro $(\mathrm{A})$ The expression of $\mathrm{ZC} 3 \mathrm{H} 15$ protein and mRNA in ZC3H15-knockdown, ZC3H15-rescued ZC3H15-knockdown and control cells were detected by Western blot and quantitative PCR analysis. (B, C) GSEA enrichment plots of cell cycle and metastasis signatures in high $\mathrm{ZC} 3 \mathrm{H} 15$ expression versus low $\mathrm{ZC} 3 \mathrm{H} 15$ expression TCGA GCs. Normalized enrichment score (NES) and false discovery rate (FDR) are shown in the plot. (D, E) MTT assays were performed on stably transfected ZC3H15-knockdown HGC-27 cells and ZC3H15-overexpressing MKN-45 cells. $(F, G)$ Soft agar assays were performed to detect the colony formation ability of GC cells. $(H, I)$ Transwell assays were used to detect the migration and invasion ability of GC cells. 

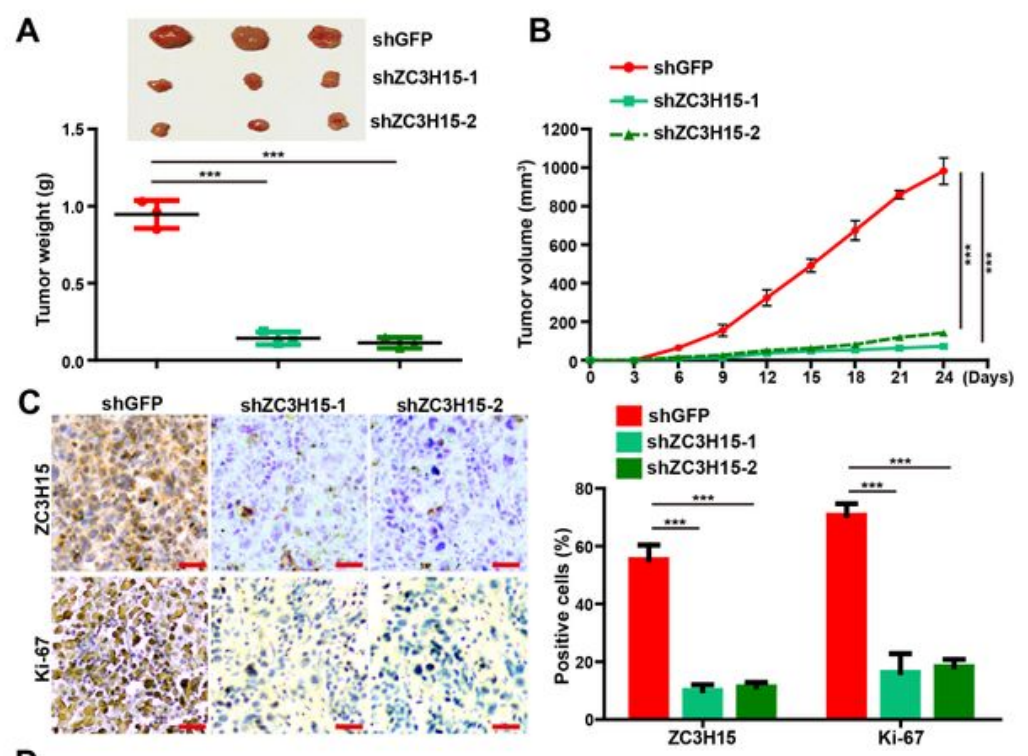

D
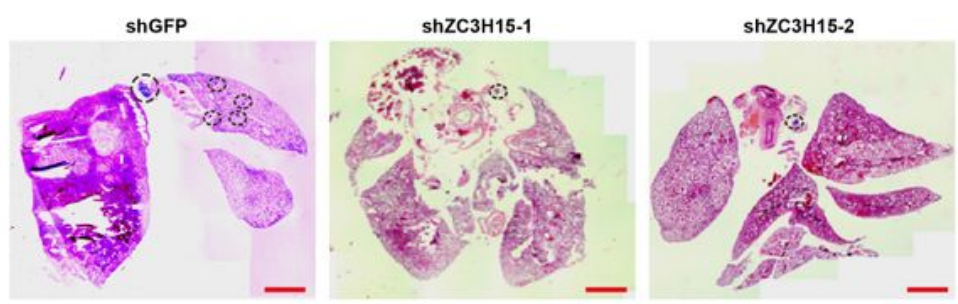

\section{Figure 4}

ZC3H15 promotes tumor growth and lung metastasis in vivo (A, B) Xenograft assays were performed in ZC3H15-knockdown HGC-27 cells. The weight and volumes of tumors were analyzed and $\mathrm{P}$ value was indicated. (C) Immunohistochemical staining assays were performed to detect the expression of $\mathrm{ZC} 3 \mathrm{H} 15$ and Ki-67 in ZC3H15-knockdown tumor tissues. (D) ZC3H15-knockdown HGC-27 cells were injected into the tail vein of SCID mice and the lungs were harvested for H\&E staining. 

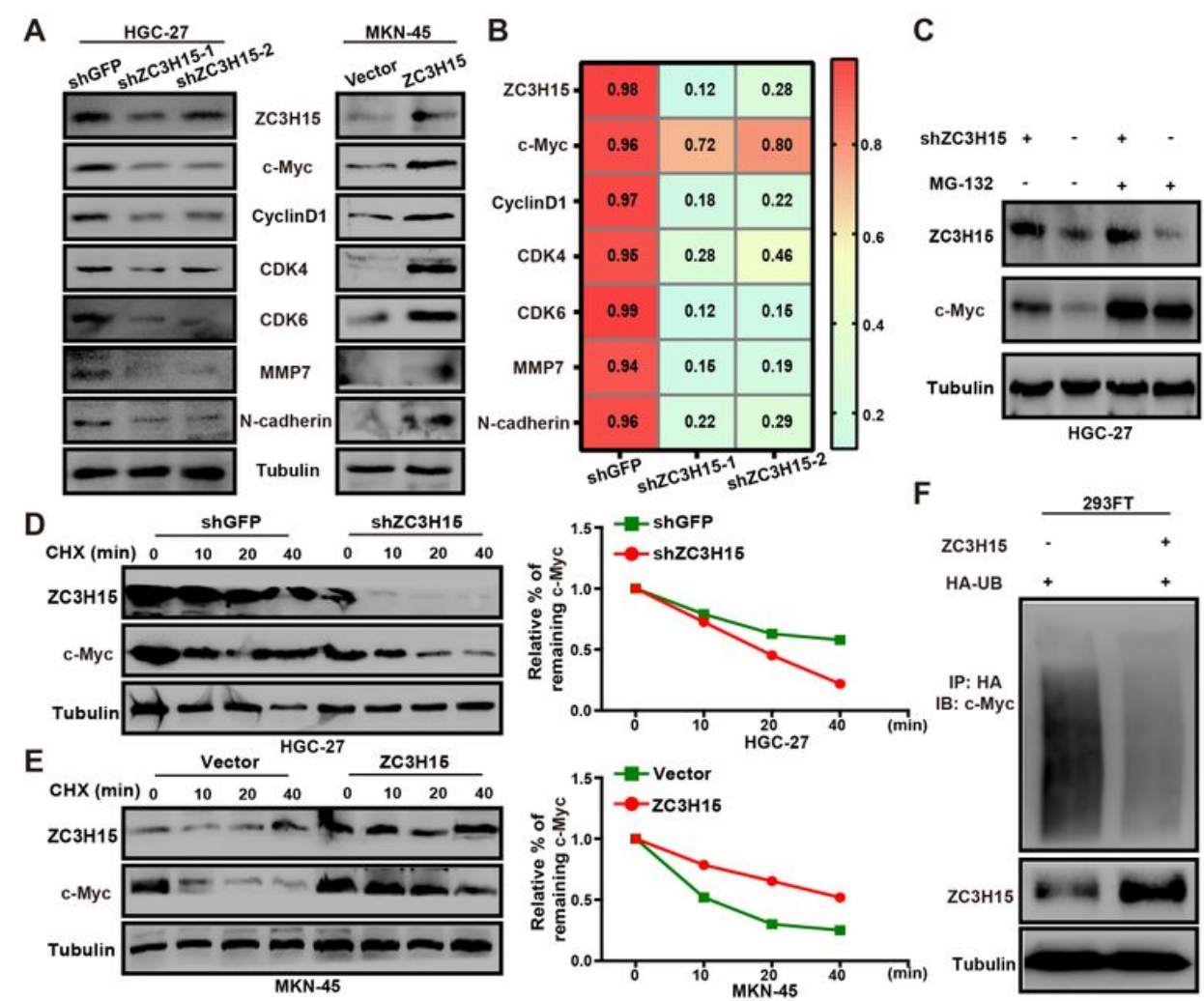

\section{Figure 5}

ZC3H15 stabilizes c-Myc by mediating its ubiquitination degradation. (A) Western blot assays were performed to detect the expression of some proteins linked to cell proliferation, migration, and invasion in ZC3H15-knockdown HGC-27 cells and ZC3H15-overexpressing MKN-45 cells. (B) RT-PCR assays were performed to detect the mRNA levels of some genes in ZC3H15-knockdown HGC-27 cells. (C) ZC3H15knockdown HGC-27 cells were treated with or without MG-132 for $6 \mathrm{~h}$ before harvesting. (D, E) The c-Myc turnover rate of ZC3H15-knockdown HGC-27 cells and ZC3H15-overexpressing MKN-45 cells were shown. Cells were treated with $\mathrm{CHX}(100 \mu \mathrm{g} / \mathrm{ml})$ for the indicated times, and then were harvested for Western blot assays. (F) Transfected cells were treated with MG-132 for $6 \mathrm{~h}$ before harvesting. The ubiquitinated c-Myc proteins were pulled down with anti-HA antibody and immunoblotted with anti-c-Myc antibody. 

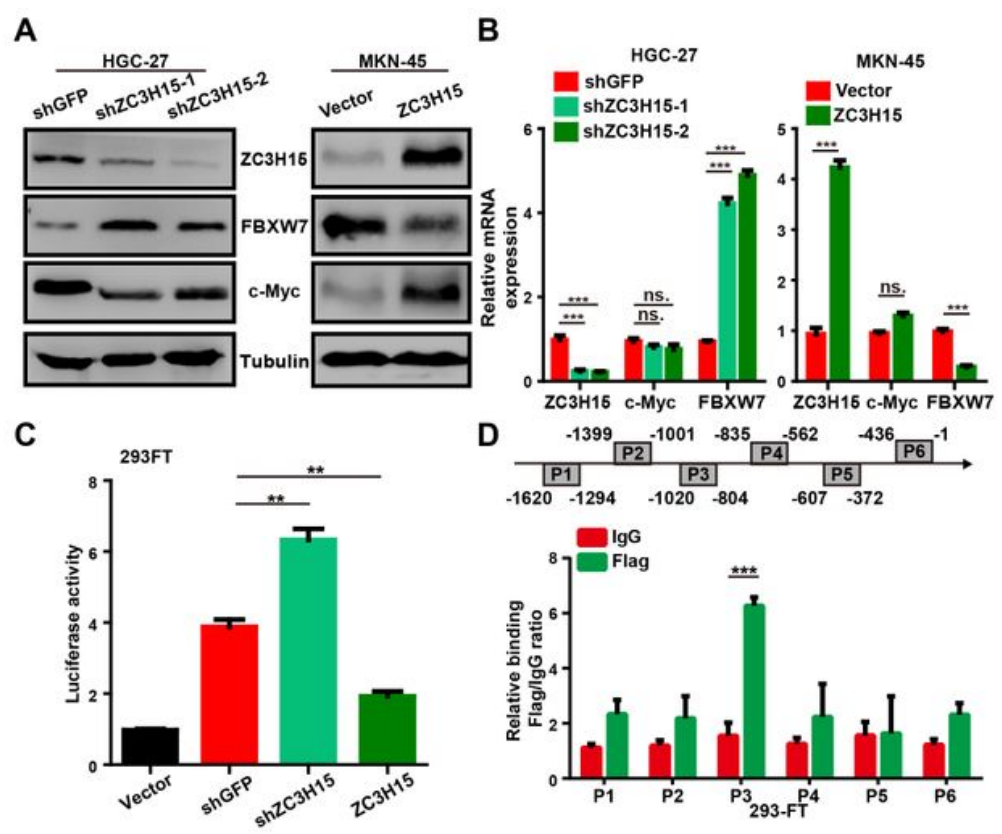

\section{Figure 6}

ZC3H15 directly inhibits the transcriptions of FBXW7 in GC cells. (A) Western blot assays were used to examine the protein expression of indicated cells. (B) Quantitative PCR assays were performed to examine the mRNA expression of indicated cells. (C) Luciferase activity was used to detect the promoter activity of FBXW7 (D) ChIP assay was performed by using Flag antibodies. IgG was used as the negative control. 


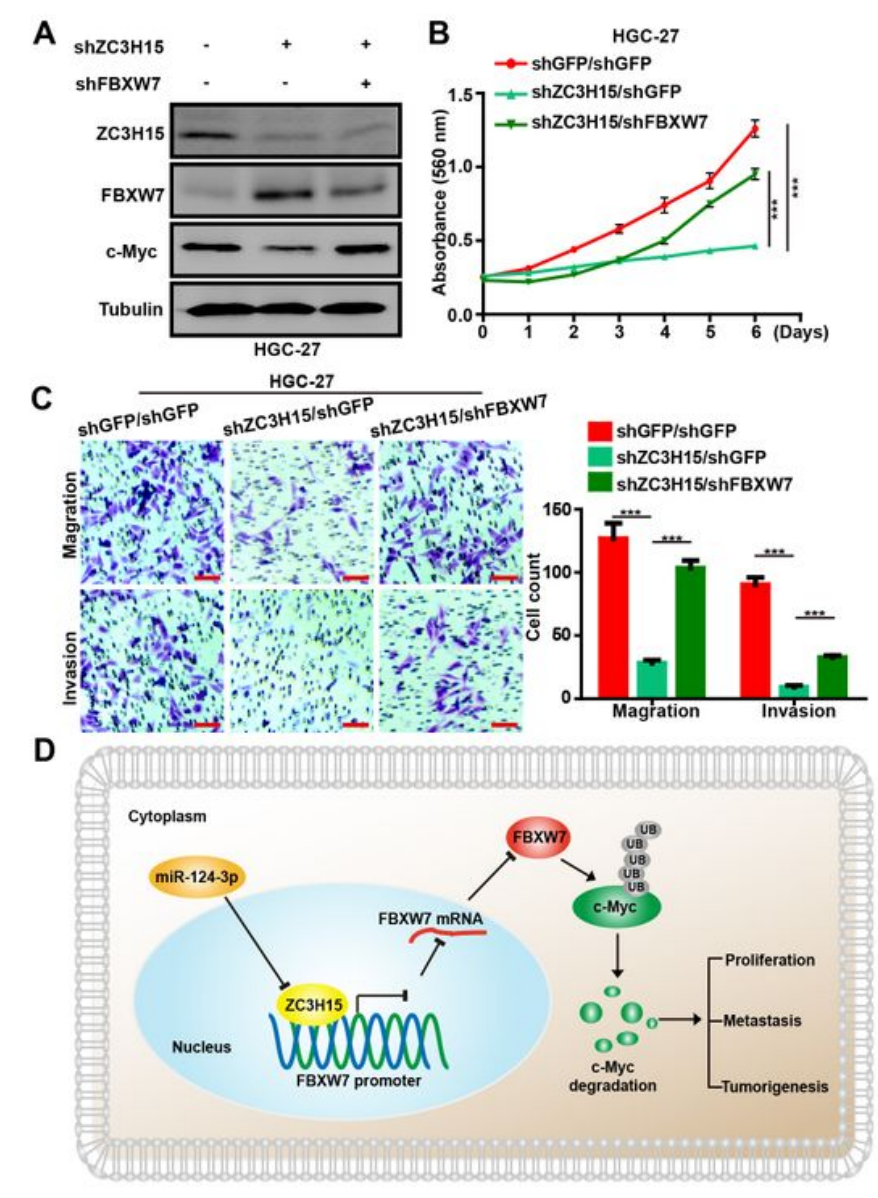

\section{Figure 7}

Downregulation of FBXW7 in ZC3H15-knockdown cells abrogates the effects induced by ZC3H15 silencing. (A) Western blot assay was performed to detect FBXW7 and c-Myc protein expression of indicated cells. (B) The effects of FBXW7 downregulation on the proliferation of ZC3H15-knockdown cells. (C) The effects of FBXW7 downregulation on the cell migration and invasion of ZC3H15knockdown cells. (D) Model of the impact of the MiR-124-3p/ZC3H15/FBXW7/c-Myc axis on regulating tumorigenesis of GC.

\section{Supplementary Files}

This is a list of supplementary files associated with this preprint. Click to download.

- FigureS3.jpg

- FigureS3.jpg

- FigureS2.jpg

- FigureS2.jpg 
- FigureS1.jpg

- FigureS1.jpg

Page 26/26 